\title{
A multi-centre quantitative assessment of moral distress amongst intensive care unit professions in the UK
}

\section{Adam Jonathan Boulton ( $\sim$ adam.boulton@nhs.net )}

University of Warwick Warwick Medical School https://orcid.org/0000-0002-2115-1129

Joyce Yeung

University of Warwick Warwick Medical School

Anne-Marie Slowther

University of Warwick Warwick Medical School

Christopher Bassford

University of Warwick Warwick Medical School

\section{Research}

Keywords: Moral distress, intensive care, ethical climate, staff wellbeing, burnout

Posted Date: August 5th, 2021

DOI: https://doi.org/10.21203/rs.3.rs-764235/v1

License: (a) (i) This work is licensed under a Creative Commons Attribution 4.0 International License.

Read Full License 


\section{Abstract}

Background:

Moral distress is a damaging experience that impacts adversely on healthcare professional wellbeing, however remains poorly studied in the UK. This study aimed to explore how widespread and severe moral distress is amongst intensive care professionals in the UK.

Methods:

Prior to the COVID-19 pandemic, a paper questionnaire that quantitatively assessed moral distress using the validated Measure of Moral Distress for Healthcare Professionals (MMD-HP) was distributed at four intensive care units of varying size and speciality facilities.

Results:

227 questionnaires were returned, including 165 nurses and 40 doctors with a mean age and ICU experience of 38.1 and 10.1 years, respectively. The median moral distress score was 108 (IQR $=78.2$, range 0 to 288). Moral distress was greatest in situations related to delivering aggressive treatment that was perceived as futile or not in the patient's best interests, closely followed by situations related to lack of resources compromising care. Moral distress was independently influenced by profession $(p=0.02)$ (nurses 117.0 vs doctors 78.0) and had no relationship with participant age and ICU experience. One-third indicated their intention to leave their current post due to moral distress and this was greater amongst nurses than doctors (37.0\% vs $15.0 \%$ ). Multiple logistic regression models included profession, gender, hospital type, age and ICU experience as covariates and had good discrimination and ability to predict intention to leave. Moral distress was associated with an intention to leave their current post in unadjusted and adjusted analyses (adjOR $=1.011$ per 1 unit increase in moral distress, $1.006-1.017, p<$ $0.0001)$ and a previous post $(\operatorname{adjOR}=1.009,1.004-1.014, p=0.001)$.

\section{Conclusions:}

Moral distress appears widespread amongst UK ICU professionals and is worse amongst nurses. Moral distress due to resource-related issues was more severe than comparable studies in North America. Its relationship with an intention to leave a post and the high proportion of ICU nurses considering leaving their current post due to moral distress is concerning, particularly as this study was performed prior to the COVID-19 pandemic. Addressing moral distress should be a priority, however the ideal interventions remain unclear.

\section{Background}

The COVID-19 pandemic has highlighted the mental challenges faced by intensive care professionals around the world, including moral distress.(1-4) The importance of staff wellbeing and welfare was recognised prior to the pandemic and is a priority for healthcare services worldwide, including the NHS. 
(5-7) Its importance is also recognised by the Royal College of Anaesthetists and Faculty of Intensive Care Medicine. $(8,9)$ Improving morale and combating burnout is also a priority(8): a key component and contributor to burnout is moral distress. $(8,10-12)$ Moral distress is a constellation of emotional and psychological features that occur when one knows the ethically correct thing to do, but is prevented from acting on that perceived obligation.(13-15) Moral distress may occur in situations that go against our moral code or that present a moral dilemma, conflict or uncertainty.(16-18) It can be deeply damaging to the individual and its features include frustration, anger, anxiety, guilt, and a sense of powerlessness.(15, $16,19,20)$ Moral distress is associated with a tendency to leave the profession and this is likely to have a negative impact on patient care. $(10,21)$

The intensive care unit (ICU) treats patients with life-threatening conditions and uses a variety of invasive and burdensome interventions.(22) Highly significant, complex, and difficult decisions are made on a regular basis.(23) Treatment in the ICU comprises complex interventions that require a multifaceted approach and interaction of a multidisciplinary team. This environment is therefore highly susceptible to moral distress and hence moral distress amongst ICU professions is of concern. $(13,17,24,25)$

Moral distress was first identified in ICU nurses in North America and has been most frequently studied in this population. $(13,17,19,24,25)$ Similar causes of moral distress have also been found amongst other ICU professionals, including physicians and respiratory therapists. $(21,26,27)$ There are differences in ICU practices, case-mix, bed provisions, and healthcare service delivery between North America and the UK. (28-32) Despite concerns over ICU staff wellbeing, burnout and moral distress in the NHS, moral distress remains poorly studied in the UK. $(18,33,34)$

This study was performed prior to the COVID-19 pandemic and its primary aim was to explore how widespread and severe the experience of moral distress is amongst ICU professionals in the UK. Secondary aims were to a) identify the most common and severe causes of moral distress; b) determine the relationship between demographic and professional characteristics and moral distress scores; $\mathrm{c}$ ) examine the relationship between moral distress and intention to leave the profession.

\section{Methods}

The NHS Health Research Authority provided approvals for the study (IRAS:238379) and the research and development (R\&D) department at University Hospitals Coventry and Warwickshire NHS Trust acted as study sponsor. The study was approved locally by each site's R\&D department.

Participants were recruited from four adult ICUs of differing size and capabilities. Sites A \& B are large tertiary care hospitals with major trauma and complex multi-specialty surgical facilities and sites $C$ \& $D$ are smaller district general hospitals with fewer specialist services. Sites $C$ and $D$ are part of the same organisational Trust so some staff work across both sites. Bed capacities of sites range from 12 to 80 beds. All full- and part-time healthcare professionals (HCP) working in the ICU were eligible. All grades and clinical professions were included, but students of any profession were excluded. 
A paper questionnaire (Supplementary File 1) was distributed between February 2019 and February 2020. Participant demographics were collected including profession, grade, age, gender, and years of ICU working experience. Moral distress was assessed quantitatively using the validated Measure of Moral Distress for Healthcare Professionals (MMD-HP).(35) The MMD-HP has superseded the revised Moral Distress Scale and is a 27-item scale that utilises a $0-4$ point Likert scale to assess the frequency with which situations arise and the intensity of the moral distress caused. $(19,35)$ These are summed to produce overall frequency and intensity scores. Individual item frequency and intensity scores are multiplied together to produce a composite item score and these summed to generate an overall moral distress score. A free text section allows participants to describe additional scenarios not included in the MMD-HP inventory. The MMD-HP also includes two related questions concerning intention to leave the profession now (Yes/No) or in the past (No, Considered but didn't leave, Left) due to moral distress.(35) Descriptive statistics were used to summarise demographics and moral distress scores. Individual item scores were ranked for comparison. Moral distress scores were non-normally distributed, as found in previous studies, $(21,33)$ and hence are presented as medians with IQRs and non-parametric statistical tests were used (Wilcoxon signed rank, Kruskal-Wallis). A sample size requirement calculation was not performed as there was inadequate UK data using the MMD-HP. Multiple linear regression was used to investigate the relationship between age and ICU experience on moral distress scores. Multiple logistic regression models were fitted to determine the association between moral distress scores and tendency to leave the profession and obtain unadjusted and adjusted odds ratios (ORs) and 95\% Cls. Covariates were pre-specified demographic and professional variables, with binary classification used for profession (nurse vs other) and hospital type (tertiary care vs district general). Discrimination of logistic regression models was assessed using area under the receiver operator curve (ROC AUC) to obtain optimal models. For tendency to leave a previous position, an ordinal logistic regression was used in accordance with the ordinal dependent variable. Statistical analyses were performed using R version 3.6.1 (R Foundation for Statistical Computing) with the code for analyses available on request.

The study received contributions from the patient and public representatives from the University Hospitals Birmingham Clinical Research Ambassador Group (https://www.invo.org.uk/communities/invodirect-org/heart-of-england-nhs-foundation-trust/). The members support the proposed study and the saw potential for the work to benefit staff wellbeing and. The group contributed to the study design, reporting and dissemination. The members also contributed to the development of study documentation, including the participant information sheet and study protocol.

\section{Results}

Two hundred and twenty-seven (227) questionnaires were returned, with 85 (37.4\%) from site A, 48 (21.1\%) from site B, 60 (26.4\%) from site C, 12 from site D (5.3\%), and 22 (9.7\%) from staff working at sites $C \&$ D. A total of 772 questionnaires were distributed across all sites, giving an overall response rate of $29.4 \%$ (site A $28.3 \%$, site B $24.0 \%$, sites C \& D 34.6\%). Participant demographics are described in Table 1. 
Table 1

Participant demographics

\begin{tabular}{|ll|}
\hline Characteristic & $\mathbf{N}=\mathbf{2 2 7}$ \\
\hline Mean age \pm SD - years & $38.1 \pm 10.3$ \\
\hline Gender - no. (\%) & \\
\hline Female & $165(72.7 \%)$ \\
\hline Male & $52(23.0 \%)$ \\
\hline Not answered & $10(4.4 \%)$ \\
\hline Profession - no. (\%) & \\
\hline Nurse & $145(63.9 \%)$ \\
\hline Doctor & $40(17.6 \%)$ \\
\hline Physiotherapist & $9(4.0 \%)$ \\
\hline Advanced Critical Care Practitioner & $8(3.5 \%)$ \\
\hline Pharmacist & $2(0.9 \%)$ \\
\hline Not answered & $23(10.1 \%)$ \\
\hline Mean ICU experience \pm SD - years & $10.1 \pm 9.2$ \\
\hline
\end{tabular}

\section{Moral distress scenarios}

Fourteen questionnaires were excluded due to missing responses preventing calculation of the moral distress score, as previously described.(35) Items are ranked by compositive score for nurses and doctors in Table 2. The most highly scored items by both nurses and doctors related to delivering aggressive treatment that was perceived as futile or not in the patient's best interests. Other highly ranked items related to lack of resources, caring for patients than is safe, excessive documentation, lack of administrative support, and abusive patients/family members compromising care. All items in the top 10 ranked by composite score for nurses and doctors were also in the top 10 when ranked by frequency or intensity score. Nurses generally rated moral distress frequency and intensity more highly than doctors. Only four of the 27 items had a greater composite score for doctors over nurses. There was no commonality in the root causes of these scenarios and included scenarios with system-level, patient-level, and team-level root causes.(35) 
Table 2

Top fifteen items ranked by composite moral distress score for nurses and doctors

\section{Situation}

Nurses

Doctors

Mean
$($ (SD) Rank $\quad \begin{aligned} & \text { Mean } \\ & \text { (SD) }\end{aligned}$ Rank

Continue to provide aggressive treatment for a person who is most likely to die regardless of this treatment when no one will make a decision to withdraw it.

$\begin{array}{llll}9.24 & 1 & 5.98 & 4 \\ (4.62) & & (3.38) & \end{array}$

Experience compromised patient care due to lack of resources/equipment/bed capacity.

8.1

$(5.15)$

2

$7.51 \quad 3$

(5.46)

3

patient care.

Follow the family's insistence to continue aggressive treatment even though I believe it is not in the best interest of the patient.

Be required to work with abusive patients/family members who are compromising quality of care.

Be required to care for more patients than I can safely care for.

Be required to work with other healthcare team members who are not as competent as patient care requires.

Witness healthcare providers giving "false hope" to a patient or family.

Be required to care for patients who have unclear or inconsistent treatment plans or who lack goals of care.

Feel pressured to order or carry out orders for what I consider to be unnecessary or inappropriate tests and treatments.

Experience lack of administrative action or support for a problem that is compromising patient care.

Witness low quality of patient care due to poor team communication.

Watch patient care suffer because of a lack of provider continuity.

Participate on a team that gives inconsistent messages to a patient/family.

Fear retribution if I speak up.

$\begin{array}{llll}7.45 & 4 & 7.45 & 1 \\ (4.24) & & (4.40) & \end{array}$

$\begin{array}{llll}6.82 & 5 & 4.03 & 7\end{array}$

(4.82) (3.93)

$\begin{array}{llll}6.60 & 6 & 6.02 & 3\end{array}$

(4.95) (5.30)

$\begin{array}{llll}6.25 & 7 & 3.02 & 15\end{array}$

(4.87) (3.57)

$\begin{array}{llll}5.62 & 8 & 4.82 & 6\end{array}$

(4.05)

(3.73)

$\begin{array}{llll}5.31 & 10 & 3.88 & 9 \\ (4.17) & & (3.25) & \end{array}$

$\begin{array}{llll}4.89 & 11 & 5.10 & 5\end{array}$

$\begin{array}{llll}4.57 & 13 & 3.37 & 13\end{array}$

(4.62)

$3.84 \quad 14$

(3.86)

2.10

(2.45)

19

3.72

15

2.20

(3.74)

6

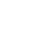

5

13

$(4.74)$

$\begin{array}{llll}5.57 & 9 & 3.75 & 10 \\ (4.71) & & (3.37) & \end{array}$

$\begin{array}{llll}4.79 & 12 & 3.30 & 14 \\ (4.11) & & (2.72) & \end{array}$

3

5

Unique free text scenarios were described by six participants (2.6\%). These were usually resource related, commonly short notice moving of staff to other critical care areas/specialties to fill staffing gaps. Other described scenarios in free text related to concerns by nurses with regard to their senior colleagues, 
because of inappropriate delegation of tasks, harassment of junior colleagues, and favouritism due to friendships.

\section{Moral distress score associations}

Total composite moral distress scores were positively skewed with a median score of 108 (IQR 78.2, range 0 to 288). The relationship between overall moral distress score and demographic characteristics are summarised in Fig. 1. Moral distress was greater in females than males (111.5 (IQR 75.5) vs 94.0 (IQR $69.3), W=4755.5, p=0.043)$. Moral distress was significantly influenced by profession $(H=11.89, p=$ 0.018) with nurses reporting greater moral distress than doctors (117.0 (IQR 65.5) vs 78.0 (IQR 73.0). There were differences in the distribution of gender across professions (Nurse: 83.7\% female; Doctor: $40.0 \%$ female). Differences in moral distress between nurses and doctors persisted after statistical adjustment for differences in gender across professions $(p=0.020)$. The significant association between gender and moral distress total was not present after accounting for the interaction between gender and profession $(p=0.44)$. There was no relationship between overall moral distress score and participant age and ICU experience. This was confirmed with multiple linear regression where an interaction effects model of age and ICU experience against overall moral distress could only explain less than $1 \%$ of the variation in moral distress (adjusted $\mathrm{R}^{2}$ 0.0089). Median moral distress scores were higher in larger tertiary care hospitals than district general hospitals, however this did not reach statistical significance (114.5 (IQR 91.8) vs 98.0 (IQR 69.9), $\mathrm{W}=5012.5 p=0.23$ ).

\section{Intention to leave the profession}

Seventy-one (33.3\%) participants indicated their intention to leave their current post due to moral distress. Twenty-eight (13.1\%) participants reported they had left a previous post due to moral distress and 101 $(47.4 \%)$ reported they had considered leaving a previous post due to moral distress but did not leave. Overall moral distress was significantly greater in those intending to leave their current post (135.5 (IQR 84.5 ) vs 88.9 (IQR 65.3), $\mathrm{W}=2771.5 p<0.0001$ ) and this difference was confirmed in both univariate and multiple logistic regression analyses. Unadjusted odds ratio of moral distress score against intention to leave was 1.011 (95\% Cl 1.006-1.017, $p<0.0001)$ per unit increase in moral distress score. Logistic regression model variable ORs are summarised in Table 3. Multiple logistic regression included profession, gender, hospital type, age and ICU experience as covariates and had good discrimination (ROC AUC 0.722) and ability to predict intention to leave (Fig. 2). Adjusted odds ratio for moral distress score against intention to leave was 1.011 (95\% Cl 1.005-1.017, $p<0.001)$. 
Table 3

Logistic regression model variables and association with intention to leave current post in univariable and multiple analyses. Italics and * indicate statistically significant association. (OR = Odds Ratio, $\mathrm{Cl}=$ Confidence Interval)

\begin{tabular}{|c|c|c|c|c|}
\hline Variable & $\begin{array}{l}\text { Univariable OR (95\% } \\
\mathrm{Cl})\end{array}$ & $p$-value & $\begin{array}{l}\text { Multivariable OR } \\
(95 \% \mathrm{Cl})\end{array}$ & $p$-value \\
\hline Age (per year) & $\begin{array}{l}0.995(0.966- \\
1.024)\end{array}$ & 0.739 & $0.982(0.929-1.036)$ & 0.516 \\
\hline $\begin{array}{l}\text { ICU experience (per } \\
\text { year) }\end{array}$ & $\begin{array}{l}1.005(0.973- \\
1.038)\end{array}$ & 0.762 & $1.009(0.929-1.072)$ & 0.781 \\
\hline \multicolumn{5}{|l|}{ Gender } \\
\hline Male & Ref & Ref & Ref & Ref \\
\hline Female & $\begin{array}{l}1.289(0.645- \\
2.679)\end{array}$ & 0.482 & $0.668(0.271-1.630)$ & 0.375 \\
\hline \multicolumn{5}{|l|}{ Profession } \\
\hline Other & Ref & Ref & Ref & Ref \\
\hline Nurse & $\begin{array}{l}3.013(1.442- \\
6.810)\end{array}$ & $0.00496^{*}$ & $3.023(1.243-8.014)$ & $0.0188^{*}$ \\
\hline \multicolumn{5}{|l|}{ Hospital type } \\
\hline District general & Ref & Ref & Ref & Ref \\
\hline Tertiary care & $1.17(0.648-2.132)$ & 0.605 & $0.953(0.466-1.948)$ & 0.895 \\
\hline $\begin{array}{l}\text { Moral distress total (per } \\
\text { unit) }\end{array}$ & $\begin{array}{l}1.011(1.006- \\
1.017)\end{array}$ & $0.0000327^{*}$ & $1.011(1.005-1.018)$ & $0.000883^{*}$ \\
\hline
\end{tabular}

A greater proportion of nurses were considering leaving their current post due to moral distress than doctors (37.0\% vs $15.0 \%)$. Nurses had a significantly greater odds of reporting an intention to leave the profession in both unadjusted (OR 3.013, 95\% $\mathrm{Cl} 1.442-6.810, p<0.01$ ) and adjusted analyses (adjOR $3.023,95 \% \mathrm{Cl} 1.243-8.014, p=0.019)$. There was no significant association between gender and intention to leave the profession in either unadjusted or adjusted models.

Moral distress score was significantly associated with the ordinal outcome of leaving a previous post in unadjusted and adjusted analyses (OR 1.010, 95\% $\mathrm{Cl} 1.006-1.015, p<0.0001$; adjOR $1.009,95 \% \mathrm{Cl}$ $1.004-1.014, p=0.001)$. Female gender and nurse profession were associated with leaving a previous post withs odds ratio of $1.914(95 \% \mathrm{Cl} 1.025-3.629, p<0.04)$ and $1.845(95 \% \mathrm{Cl} 1.017-3.386, p<0.05)$ respectively. These significant associations did not persist in adjusted analyses (female gender adjOR 1.188, 95\% Cl 0.554-2.560, $p=0.659$; nurse profession adjOR 1.460, 95\% $\mathrm{Cl} 0.705-3.059, p=0.310$ ). Ordinal logistic regression model variable ORs are summarised in Table 4. 
Table 4

Logistic regression model variables and association with the ordinal dependent variable of intention to leave previous post due to moral distress (No, Considered but didn't leave, Left) in univariable and multiple analyses. Italics and * indicate statistically significant association. (OR = Odds Ratio, $\mathrm{Cl}=$

Confidence Interval)

\begin{tabular}{|c|c|c|c|c|}
\hline Variable & $\begin{array}{l}\text { Univariable OR (95\% } \\
\mathrm{Cl})\end{array}$ & $p$-value & $\begin{array}{l}\text { Multivariable OR } \\
(95 \% \mathrm{Cl})\end{array}$ & $p$-value \\
\hline Age (per year) & $\begin{array}{l}1.021(0.994- \\
1.049)\end{array}$ & 0.128 & $1.040(0.992-1.093)$ & 0.106 \\
\hline ICU experience (per year) & $\begin{array}{l}1.018(0.989- \\
1.049)\end{array}$ & 0.226 & $0.965(0.914-1.019)$ & 0.201 \\
\hline \multicolumn{5}{|l|}{ Gender } \\
\hline Male & Ref & Ref & Ref & Ref \\
\hline Female & $\begin{array}{l}1.914(1.025- \\
3.629)\end{array}$ & $0.0436^{*}$ & $1.188(0.554-2.560)$ & 0.659 \\
\hline \multicolumn{5}{|l|}{ Profession } \\
\hline Other & Ref & Ref & Ref & Ref \\
\hline Nurse & $\begin{array}{l}1.845(1.017- \\
3.386)\end{array}$ & $0.0455^{*}$ & $1.460(0.705-3.059)$ & 0.310 \\
\hline \multicolumn{5}{|l|}{ Hospital type } \\
\hline District general & Ref & Ref & Ref & Ref \\
\hline Tertiary care & $\begin{array}{l}1.707(1.002- \\
2.929)\end{array}$ & 0.0504 & $1.738(0.937-3.249)$ & 0.0805 \\
\hline $\begin{array}{l}\text { Moral distress total (per } \\
\text { unit) }\end{array}$ & $\begin{array}{l}1.010(1.006- \\
1.015)\end{array}$ & $0.0000113^{*}$ & $1.009(1.004-1.014)$ & $0.00122^{*}$ \\
\hline
\end{tabular}

\section{Discussion}

This is the largest study of moral distress in the UK to date and the first to use a multi-centre approach with assessment across ICU professions. Included ICUs were at both district general and teaching hospitals and were of varying size and sub-specialty capability. Moral distress was widespread across included sites and across ICU professions. Moral distress scores were highest in situations related to delivering aggressive treatment that was perceived as futile or not in the patient's best interests, closely followed by lack of resources compromising delivered care. Moral distress was significantly worse in nurses and was not influenced by age or years of ICU experience. There was, as expected, a strong association between higher moral distress scores and intention to leave their current post. There was also a significant relationship between moral distress and leaving a previous post. These associations persisted in adjusted analyses and underlines the impact moral distress may have on ICU staff retention. It is concerning that one third of participants reported an intention to leave their current post due to moral 
distress. This study took place before the COVID-19 pandemic and it is possible the immense pressures on UK ICU services has impacted the experience of moral distress. This should be recognised when considering how this study reflects the current welfare of UK ICU professionals.

This is the first published use of the most up to date quantitative measure of moral distress (MMD-HP) in a UK healthcare setting.(35) Free text scenarios distinct from MMD-HP items were rarely described. Our study also included a qualitative assessment by semi-structured interviews (data presented elsewhere) and no interview participant described scenarios distinct from the MMD-HP items. With this in mind and considering the inclusion of a range of ICU professions and participants from multiple ICUs of different size and sub-specialty, this study gives support for use of the MMD-HP in UK research.

The only other quantitative study of moral distress in UK ICUs to date also found moral distress was significantly associated with an intention to leave a post, a finding consistent with international literature. $(15,21,33,36)$ It is increasingly clear that the impact of moral distress appears damaging to staff retention and should be considered by employers. $(11,15)$ Colville et al. were unable to detect a difference in moral distress scores between nurses and doctors and highlight the confounding impact of gender differences. Our larger study found that moral distress in greater in nurses and this difference remained statistically significant after accounting for differences in gender distributions. This finding is consistent with international study showing that nurses report greater moral distress than doctors. $(21,35,36)$ This could be due to differences in ability to influence decision-making, lack of clinical information sharing between colleagues, and practical differences in how direct clinical care is delivered.(15) Lack of agency has been cited as a driver of moral distress; a phenomenon that may not occur equally between professions.(16) The difference between ICU professions in moral distress and intention to leave the profession should be reflected upon when considering delivery of possible interventions to alleviate moral distress. It is also notable that nurses had a significantly greater intention to leave the profession, including in adjusted analyses. Indeed, $37 \%$ of nurses included in our study indicated they were considering leaving their current post due to moral distress, compared with $15 \%$ of doctors, a concerning finding that potentially has staff retention and workplace planning implications.

There was a signal toward increased moral distress at larger tertiary care hospitals compared to district general hospitals, however this did not reach statistical significance. If there is a true difference this could reflect differences in clinical case-mix between units or could be due to differences in team size impacting staff wellbeing and ability to cope with moral distress. This finding deserves further investigation, particularly given possible future changes to the provision of UK critical care services toward larger units on a hub-and-spoke model.(37)

No correlation was found between ICU experience and moral distress score, therefore not lending support to the crescendo effect or the concept of moral residue.(38) The crescendo effect was proposed to explain the phenomenon of increasing moral distress after repeated exposure to similar situations, and it may be linked with formation of moral residue after a distressing event.(15, 19, 38) Not all moral distress research has demonstrated the crescendo effect or moral residue. $(33,36)$ Failure to capture the 
crescendo effect could be a result of study selection bias. It is increasingly clear that moral distress is associated with an intention to leave the profession, therefore those experiencing a crescendo effect may leave the profession and consequently not be included in snapshot studies. To empirically demonstrate the crescendo effect, longitudinal studies would be required.

Overall moral distress scores were higher in our study than similar research in the USA.(35) Mean moral distress scores were higher in our study across all profession subgroups.(35) At present, there is no other international use of this most up to date quantitative moral distress measure (the MMD-HP) to make further comparisons. Past studies have used the previous version (the Moral Distress Scale - Revised) which uses 21 items, compared with the MMD-HP's 27, therefore precluding direct comparison. A recent study in Ireland during the COVID-19 pandemic does use the MMD-HP, but only selected items and so overall comparisons cannot be made.(39) Almost all highly ranked individual item composite scores were higher in our study than that in the USA.(35) This was most notable for resource-related items, specifically compromised care due to lack of resources/equipment/bed capacity, where the composite moral distress score was substantially higher in our UK study. This was ranked the second highest item by moral distress score in our study for both doctors and nurses, but ranked fifth in a comparative study in the USA.(35) This could reflect differences in healthcare delivery and the provision of critical care beds. (30-32) This high signal of moral distress raises a worrying concern that sub-optimal care may be being delivered due to resource constraints. This study is unable to determine if this is occurring, nevertheless the high levels of moral distress due to resource-related issues should be noted.

Whilst this research has focussed on intensive care practice, it seems unlikely that moral distress is a unique experience to the intensive care speciality. This study has shown moral distress occurs across healthcare professions within intensive care and across multiple ICUs. For example, moral distress may occur when healthcare professionals refer patients to intensive care, particularly if these patients are not admitted to the ICU; an area that remains unstudied. Future study in other clinical specialties appears prudent given the damaging nature of moral distress.

Our study has several limitations. Firstly, the study is at risk of selection bias. Those experiencing high levels of moral distress may be unwilling to complete the questionnaire, or alternatively those with low levels of moral distress may not appreciate its value and not take part. We only included those currently working in ICU and so cannot capture those that may have left ICU due to high levels of moral distress. We attempted to improve external validity by including multiple ICUs which had different operational characteristics. Secondly, there are more nurses than other professions in our sample, however this reflects the distribution of ICU professions.(22) Thirdly, this study is a snapshot and may be influenced by how the participant is feeling at that time, or what clinical cases are present on their unit. Moral distress may be a reactive process and be influenced by experiences at that point in time.(40) It is possible that moral distress may fluctuate and change as the clinical case-mix within an ICU changes. It remains unknown how moral distress changes over time and further study is warranted.

\section{Conclusions}


This study highlights the widespread nature of moral distress in UK ICUs and across ICU professions. Moral distress is worst in situations related to delivery of aggressive treatment perceived as futile or not in the patient's best interests, in keeping with previous international research. Moral distress in UK ICUs appears greater than studies in North America, particularly regarding moral distress related to resource constraints. Moral distress is greatest in nurses and is independently associated with an intention to leave the profession, both at present and in the past. This study took place before the COVID-19 pandemic and, worryingly, one third of participants were considering leaving their current position. Moral distress is therefore a pressing problem for NHS trusts and policymakers seeking to retain and support an effective ICU workforce, however the ideal interventions to alleviate moral distress and support staff wellbeing remain unclear and demand further study.

\section{Abbreviations}

adjOR

adjusted odds ratio

ICU

Intensive Care Unit

IQR

Interquartile range

MMD-HP

Measure of Moral Distress for Healthcare Professionals

NHS

National Health Service

OR

Odds ratio

ROC AUC

Area under the receiver operator curve

UK

United Kingdom

USA

United States of America

\section{Declarations}

Ethics approval and consent to participate: Approvals gained from the NHS Health Research Authority (IRAS:238379). University Hospitals Coventry and Warwickshire NHS Trust acted as study sponsor. Local approvals from each study site Research \& Development department.

Consent for publication: Not applicable 
Availability of data and materials: The datasets used and/or analysed during the current study are available from the corresponding author on reasonable request.

Competing interests: Authors identify no conflicts of interest.

Funding: Funded by an Association of Anaesthetists/Anaesthesia research grant administered by the National Institute of Academic Anaesthesia. AJB is supported by an NIHR funded Academic Clinical Fellowship. The funder had no role in the study design, data collection, analysis, or its interpretation, or writing of the manuscript.

Author's contributions: Study design: AJB, JY, AMS, CB. Study conduct: AJB, JY, CB. Data analysis: AJB. Drafting of manuscript: AJB. Review of manuscript: AJB, JY, AMS, CB.

Acknowledgements: We are grateful for the expert statistical support provided by Dr Georgios Bouliotis, University of Warwick, UK. We sincerely thank all the participants for voluntarily completing the questionnaires. The NIHR Clinical Research Network adopted this study onto their portfolio and the support of the research teams at all sites is greatly appreciated. We are very grateful for the PPI input and contributions made by the University Hospitals Birmingham Clinical Research Ambassador Group.

\section{References}

1. Dzau VJ, Kirch D, Nasca T. Preventing a Parallel Pandemic - A National Strategy to Protect Clinicians' Well-Being. N Engl J Med. 2020;383(6):513-5.

2. Greenberg N, Docherty M, Gnanapragasam S, Wessely S. Managing mental health challenges faced by healthcare workers during covid-19 pandemic. BMJ. 2020;368:m1211.

3. Shapiro J, McDonald TB. Supporting Clinicians during Covid-19 and Beyond - Learning from Past Failures and Envisioning New Strategies. N Engl J Med. 2020;383(27):e142.

4. Sheather J, Fidler H. Covid-19 has amplified moral distress in medicine. BMJ. 2021;372:n28.

5. NHS Health Education England. NHS Staff and Learners' Mental Wellbeing Commission report. 2019.

6. Hall LH, Johnson J, Watt I, Tsipa A, O'Connor DB. Healthcare Staff Wellbeing, Burnout, and Patient Safety: A Systematic Review. PloS one. 2016;11(7):e0159015-e.

7. McClelland L, Plunkett E, McCrossan R, Ferguson K, Fraser J, Gildersleve C, et al. A national survey of out-of-hours working and fatigue in consultants in anaesthesia and paediatric intensive care in the UK and Ireland. Anaesthesia. 2019;74(12):1509-23.

8. Royal College of Anaesthetists. A report on the welfare, morale and experiences of anaesthetists in training: the need to listen. 2017.

9. Highfield J, Parry-Jones J. Professional Quality of Life in intensive care medicine: The 2018 Faculty of Intensive Care Medicine Workforce survey. Journal of the Intensive Care Society. 2019;21(4):299304. 
10. Lamiani G, Borghi L, Argentero P. When healthcare professionals cannot do the right thing: $A$ systematic review of moral distress and its correlates. J Health Psychol. 2017;22(1):51-67.

11. Fumis RRL, Junqueira Amarante GA, de Fátima Nascimento A, Vieira Junior JM. Moral distress and its contribution to the development of burnout syndrome among critical care providers. Ann Intensiv Care. 2017;7(1):71-.

12. Dzeng E, Curtis JR. Understanding ethical climate, moral distress, and burnout: a novel tool and a conceptual framework. 2018;27(10):766-70.

13. Elpern EH, Covert B, Kleinpell R. Moral distress of staff nurses in a medical intensive care unit. American journal of critical care: an official publication. American Association of Critical-Care Nurses. 2005;14(6):523-30.

14. Jameton A. Nursing practice: The ethical issues. New Jersey: Prentice Hall Inc; 1984.

15. Hamric AB. Empirical research on moral distress: issues, challenges, and opportunities. HEC forum: an interdisciplinary journal on hospitals' ethical legal issues. 2012;24(1):39-49.

16. Morley G, Ives J, Bradbury-Jones C, Irvine F. What is 'moral distress'? A narrative synthesis of the literature. Nurs Ethics. 2017;26(3):646-62.

17. Choe K, Kang Y, Park Y. Moral distress in critical care nurses: a phenomenological study. Journal of advanced nursing. 2015;71(7):1684-93.

18. Morley G, Bradbury-Jones C, Ives J. What is 'moral distress' in nursing? A feminist empirical bioethics study. Nurs Ethics. 2020;27(5):1297-314.

19. Hamric AB, Borchers CT, Epstein EG. Development and Testing of an Instrument to Measure Moral Distress in Healthcare Professionals. AJOB Primary Research. 2012;3(2):1-9.

20. Austin W, Lemermeyer G, Goldberg L, Bergum V, Johnson MS. Moral distress in healthcare practice: the situation of nurses. Alberta RN. 2008;64(4):4-5.

21. Dodek PM, Wong H, Norena M, Ayas N, Reynolds SC, Keenan SP, et al. Moral distress in intensive care unit professionals is associated with profession, age, and years of experience. $\mathrm{J}$ Crit Care. 2016;31(1):178-82.

22. The Faculty of Intensive Care Medicine. Intensive Care Society. Guidelines for the provision of intensive care services. Edition 2. 2019.

23. Sprung CL, Cohen SL, Sjokvist P, Baras M, Bulow HH, Hovilehto S, et al. End-of-life practices in European intensive care units: the Ethicus Study. Jama. 2003;290(6):790-7.

24. Corley MC. Moral distress of critical care nurses. American journal of critical care: an official publication. American Association of Critical-Care Nurses. 1995;4(4):280-5.

25. Rodney P. Moral distress in critical care nursing. Canadian critical care nursing journal. 1988;5(2):911.

26. Henrich NJ, Dodek PM, Alden L, Keenan SP, Reynolds S, Rodney P. Causes of moral distress in the intensive care unit: A qualitative study. Journal of critical care. 2016;35:57-62. 
27. Schwenzer KJ, Wang L. Assessing moral distress in respiratory care practitioners. Critical care medicine. 2006;34(12):2967-73.

28. Murthy S, Wunsch $\mathrm{H}$. Clinical review: International comparisons in critical care - lessons learned. Crit Care. 2012;16(2):218.

29. Wunsch H, Angus DC, Harrison DA, Linde-Zwirble WT, Rowan KM. Comparison of medical admissions to intensive care units in the United States and United Kingdom. Am J Respir Crit Care Med. 2011;183(12):1666-73.

30. Wallace DJ, Angus DC, Seymour CW, Barnato AE, Kahn JM. Critical Care Bed Growth in the United States. A Comparison of Regional and National Trends. Am J Respir Crit Care Med. 2014;191(4):410-6.

31. Wong DJN, Popham S, Wilson AM, Barneto LM, Lindsay HA, Farmer L, et al. Postoperative critical care and high-acuity care provision in the United Kingdom, Australia, and New Zealand. Br J Anaesth. 2019;122(4):460-9.

32. Böhm K, Schmid A, Götze R, Landwehr C, Rothgang H. Five types of OECD healthcare systems: Empirical results of a deductive classification. Health Policy. 2013;113(3):258-69.

33. Colville G, Dawson D, Rabinthiran S, Chaudry-Daley Z, Perkins-Porras L. A survey of moral distress in staff working in intensive care in the UK. Journal of the Intensive Care Society. 2018.

34. St Ledger U, Begley A, Reid J, Prior L, McAuley D, Blackwood B. Moral distress in end-of-life care in the intensive care unit. Journal of advanced nursing. 2013;69(8):1869-80.

35. Epstein EG, Whitehead PB, Prompahakul C, Thacker LR, Hamric AB. Enhancing Understanding of Moral Distress: The Measure of Moral Distress for Health Care Professionals. AJOB Empir Bioeth. 2019;10(2):113-24.

36. Whitehead PB, Herbertson RK, Hamric AB, Epstein EG, Fisher JM. Moral distress among healthcare professionals: report of an institution-wide survey. Journal of nursing scholarship: an official publication of Sigma Theta Tau International Honor Society of Nursing. 2015;47(2):117-25.

37. Suntharalingam G, Handy J, Walsh A. Regionalisation of critical care: can we sustain an intensive care unit in every hospital? Anaesthesia. 2014;69(10):1069-73.

38. Epstein EG, Hamric AB. Moral distress, moral residue, and the crescendo effect. J Clin Ethics. 2009;20(4):330-42.

39. Ffrench-O'Carroll R, Feeley T, Tan MH, Magner C, L'Estrange K, Efrimescu C-I, et al. Psychological impact of COVID-19 on staff working in paediatric and adult critical care. British journal of anaesthesia. 2020:S0007-912(20)30824-2..

40. Jameton A. Dilemmas of moral distress: moral responsibility and nursing practice. AWHONN's clinical issues in perinatal and women's health nursing. 1993;4(4):542-51.

\section{Figures}



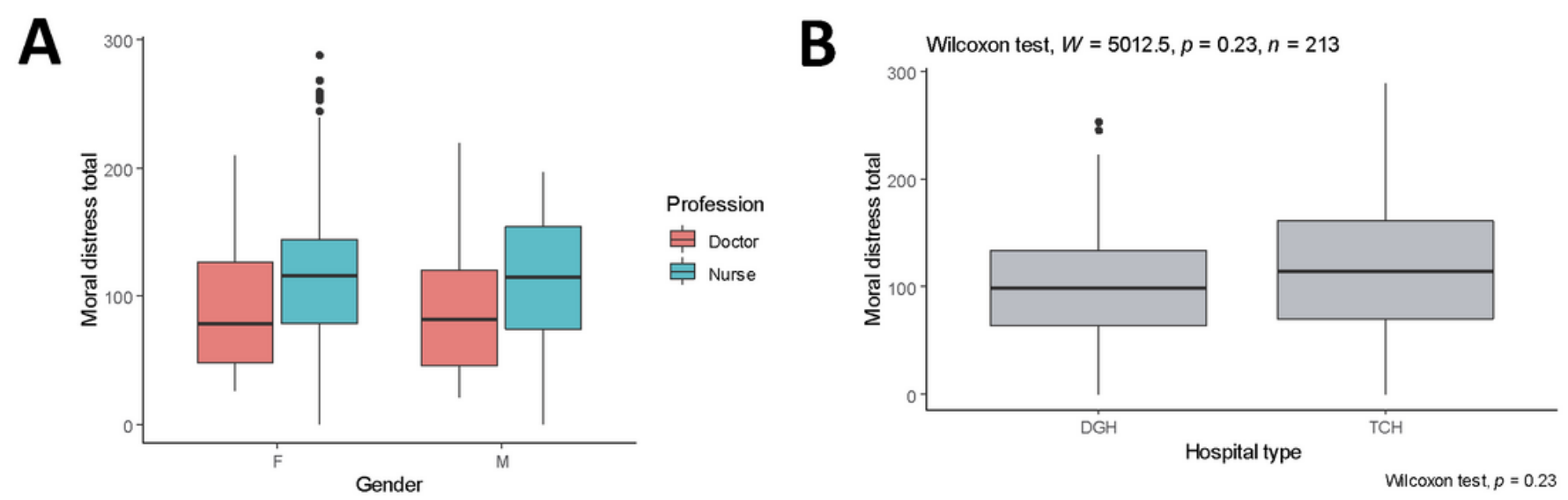

C

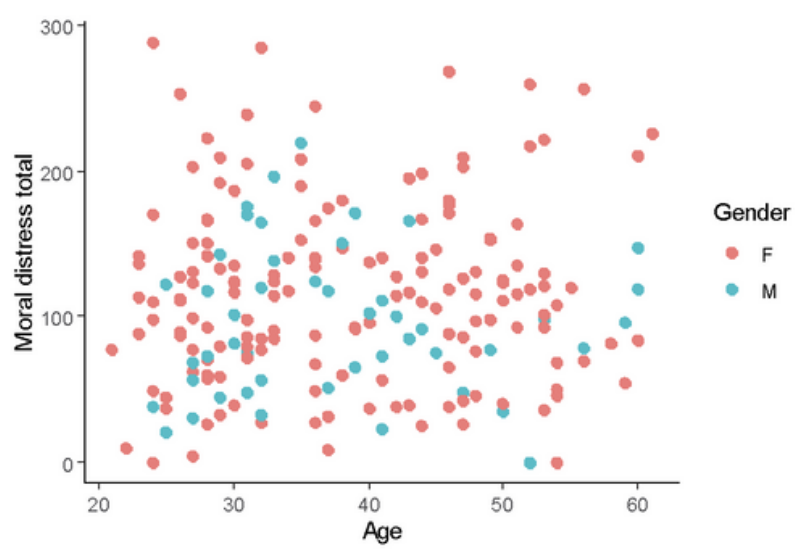

D

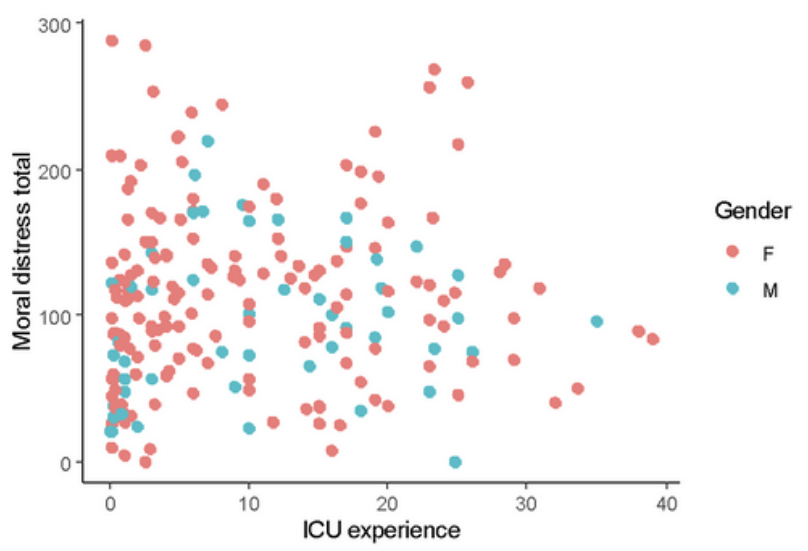

\section{Figure 1}

Relationship between moral distress total and demographic/professional variables. F=Female, $M=M a l e$, DGH=District General Hospital, $\mathrm{TCH}=$ Tertiary Care Hospital. N=213 as 14 questionnaires excluded due to missing responses preventing calculation of the moral distress score. 


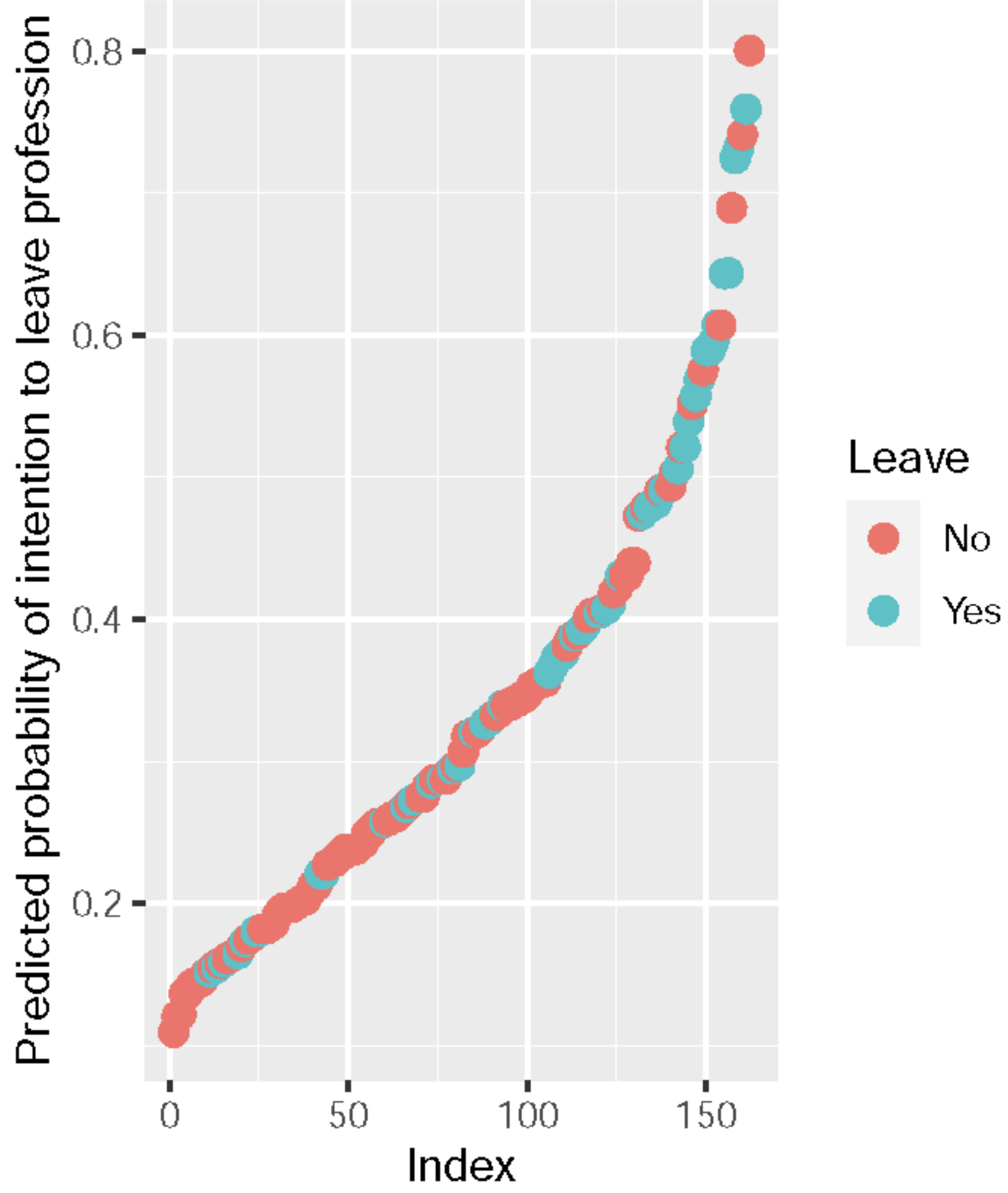

Figure 2

Multivariable logistic regression model prediction of intention to leave current post due to moral distress.

\section{Supplementary Files}

This is a list of supplementary files associated with this preprint. Click to download. 
- SupplementaryFile1.docx

Page 18/18 